\title{
Carry Funding and Safe Haven Currencies: A Threshold Regression Approach
}

\author{
Oliver Hossfeld \\ Ronald MacDonald
}

\author{
CESIFO WORKING PAPER NO. 5117 \\ CATEGORY 7: MONETARY POLICY AND INTERNATIONAL FINANCE \\ DECEMBER 2014
}

An electronic version of the paper may be downloaded

- from the SSRN website:

- from the RePEc website:

- from the CESifo website:

WWW.SSRN.com

Www.RePEc.org

www.CESifo-group.org/wp

\section{CESifo}




\title{
Carry Funding and Safe Haven Currencies: A Threshold Regression Approach
}

\begin{abstract}
In this paper, we analyze which currencies can be regarded as safe haven currencies. Our empirical approach allows us to distinguish between a low- and high stress regime, and to control for the impact of carry trade reversals and other fundamental determinants. We therefore address the question of whether a supposed safe haven currency only appreciates in times of crises because carry trades are unwound, in which the corresponding currency has served as funding currency, or whether it possesses "true" safe haven qualities; i.e. it provides a hedge against global stock market losses in stressful times even after controlling for the impact of carry trade reversals. The latter issue has largely been brushed aside in the extant literature but has important policy implications for the justification of central bank FX interventions in times of crises. According to the estimation results, two currencies, the Swiss franc and (to a lesser extent) the US dollar qualify as safe haven currencies, and the euro serves as a hedge currency. Results for the yen support its role as a carry funding vehicle, but not necessarily that of a safe haven currency. While the focus is on effective exchange rates, the paper also contains a separate analysis of bilateral euro-based exchange rates, given the euro's prominent role during the euro area sovereign debt crisis.
\end{abstract}

JEL-Code: C320, F310.

Keywords: nonlinear regression, threshold model, safe haven, carry trade.

\author{
Oliver Hossfeld* \\ Deutsche Bundesbank \\ Wilhelm-Epstein-Str. 14 \\ Germany-60431 Frankfurt/Main \\ oliver.hossfeld@bundesbank.de
}

\author{
Ronald MacDonald \\ University of Glasgow, Adam Smith \\ Business School, Department of Economics \\ UK - G12 8RT Glasgow, Scotland \\ R.Macdonald@lbss.gla.ac.uk
}

*corresponding author

November 12, 2014

This work represents the authors' personal opinions and does not necessarily reflect the views of the Deutsche Bundesbank. The authors thank Wilhelm Althammer, Markus Baltzer, Menzie Chinn, Richard Clarida, Christoph Fischer, Ulrich Grosch, Heinz Herrmann, seminar participants at the Bundesbank and participants at the Columbia-Tsinghua Conference on International Economics for helpful comments. 


\section{Introduction}

After the Swiss franc (CHF) moved towards parity with the euro (EUR) in mid 2011, the Swiss National Bank (SNB) announced a minimum exchange rate of 1.20 CHF/EUR. It argued that the "massive overvaluation" of the franc was a threat to the Swiss economy and was causing risks of arising deflationary pressures. ${ }^{1}$ In a rare congruence, analysts attributed the dramatic appreciation of the franc relative to the euro as well as in effective terms preceding the announcement to Switzerland's status as a safe haven - a place to which investors resort to in times of high financial stress. Correspondingly, the CHF has frequently been called a safe haven-currency. A perusal of media sources as well as the economics literature reveals that it is not the only currency to which the label of a "safe haven currency" has been attached. Other currencies that have (more or less frequently) been called safe haven-currencies include the yen (JPY), the US dollar (USD), the pound sterling (GBP) and the EUR. More generally, previous empirical results suggest that low interest-currencies typically depreciate smoothly in "risk-on" episodes but appreciate abruptly in "risk-off" episodes (see, among others, Brunnermeier et al. (2009), Burnside et al. (2011), as well as Gagnon and Chaboud (2007)). But should all low interest currencies which appreciate in times of crisis be called "safe haven currencies"?

While the appreciation of low interest currencies in times of crisis might be due to their perceived safe haven status, this pattern is also consistent with an unwinding of open carry trade positions, in which these currencies served as funding currencies. ${ }^{2}$ Obviously, it makes a crucial difference, what the underlying cause for a currency's appreciation in times of crisis is, not least from a policy perspective. If a country issues a currency which is widely used to fund carry trades, its international competitiveness is likely to benefit from a steady depreciation of its currency in tranquil times. A reversal, at least in principal, then "just" reverses previous gains in competitiveness. In our view, a "true" safe haven currency does not (only) appreciate because it served as a carry funding currency but because it is generally regarded as being safe by investors. ${ }^{3}$ As a consequence, countervailing policy measures seem more comprehensible in the latter than in the former case. Beside the impact of carry trade reversals or "true" safe haven flows, the appreciation of a currency in times of crisis might also (at least partly) be due to the (possibly different) impact of other "classic" exchange rate determinants, unrelated

\footnotetext{
${ }^{1}$ For details see the respective $\mathrm{SNB}$ press release from September 6, 2011 downloadable at http://www.snb.ch/en/mmr/reference/pre_20110906/source/pre_20110906.en.pdf.

${ }^{2}$ When investors follow a carry strategy, they sell short a (low interest) funding currency (such as the JPY) and simultaneously buy a (high interest) target currency. This induces excess supply of the funding currency and excess demand for the target currency. In times of crisis, such a strategy might appear too risky to the investors and lead them to suddenly unwind their open positions, exerting sudden upward pressure on the funding currency.

${ }^{3}$ Empirically, it is, however, hard to identify the underlying cause of the appreciation because both carry unwinding and safe haven flows are triggered by high financial stress and result in an appreciation of the funding/safe haven currency.
} 
to safe haven flows or carry trade reversals.

Following this discussion, the aim of our paper is to determine which of the G10 currencies really qualify as safe haven currencies. Anticipating our approach, we define a currency to be a safe haven currency if its effective returns are significantly negatively related to global stock market returns in times of high financial stress, even when controlling for the impact of carry trades (respectively, their reversal) and the possibly regime-specific impact of fundamental exchange rate determinants. To this end, we estimate Hansen (2000) threshold regressions for G10 effective exchange rate returns, where country-specific financial stress-threshold values separating the low from the high stress-regime are determined endogenously and tested for significance.

More specifically, the contributions of this paper are as follows. First, we provide a clear definition of when a currency should be regarded as a safe haven currency. Second, we analyze which of the G10-currencies qualify as safe haven currencies according to our criteria and estimation results. Third, in contrast to the previous literature, we analyze effective as opposed to bilateral exchange rates. This allows us to gauge the impact of a currency's safe haven status on the international price competitiveness of the respective economy (given the high comovement between G10 nominal and real effective exchange rates at least in the short run). ${ }^{4}$ Furthermore, if bilateral currency pairs are analyzed separately, we would only be able to infer whether a particular currency acts as a safe haven relative to one other currency, and not in an absolute sense, which is what we really think of when speaking about a "safe haven currency". Fourth, we analyze whether the impact of fundamental exchange rate determinants differs between the the high- and the low stress-regimes (in case the empirical evidence points towards the presence of two regimes). Finally, we provide a systematic classification table of the G10 currencies into hedge, safe haven, carry funding, and speculative currencies. The classification is based on previously defined criteria and, thereby, avoids the arbitrariness with which currencies are sometimes given certain attributes in the financial press. Analysts seem to resort to explanations involving safe haven flows or carry trades quite often in situations in which other plausible fundamentals-based explanations for currency movements are missing. ${ }^{5}$

The structure of the paper is as follows. In section 2, we present some descriptive evidence on safe haven and carry funding currencies as well as a selective review of the related literature. In section 3, we motivate our econometric model and describe the data used in the analysis. In section 4 , the estimation results for the G10 currencies are presented. In addition, this

\footnotetext{
${ }^{4}$ As noted by Cheung et al. (2007) "...trade weighted rates are to be preferred to bilateral rates since the reliance on the latter can lead to misleading inferences about overall competitiveness".

${ }^{5}$ See Ranaldo and Söderlind (2010) for an overview of conflicting statements in the financial press regarding currencies' safe haven status.
} 
section includes further results for EUR-based bilateral exchange rates. Section 5 concludes and summarizes the main findings.

\section{Related literature and some descriptive evidence}

Our paper relates to five strands of literature: First, and most closely, to the literature explicitly dealing with safe haven currencies, such as Ranaldo and Söderlind (2010) and Habib and Stracca (2012). Second, to the empirical finance literature on safe haven assets in general (Baur and Lucey (2010)), from which we take our definition of a safe haven currency. Third, to the literature on (the average profitability of) carry trades and their exposure to crash risk (among others, Brunnermeier et al. (2009)). Fourth, to the literature documenting the violation of the uncovered interest parity (UIP) condition based on "Fama-regressions" (Froot and Thaler (1990) and Engel (2013)), the so called "forward premium puzzle". ${ }^{6}$ Fifth, to the literature (at least partially) resurrecting the UIP-condition, such as Clarida et al. (2009), showing that results from "Fama-regressions" are regime-specific, or Chinn and Meredith (2005) as well as Mehl and Cappiello (2009), suggesting that evidence against UIP is clearer at short than at long horizons. ${ }^{7}$

One of the few studies explicitly dealing with safe haven currencies is Habib and Stracca (2012). They analyze the fundamental drivers of safe haven currencies. To this end, they perform various panel regressions, in which bilateral USD-based exchange rate returns of 52 countries are regressed on a number of fundamental determinants as well as interaction terms of these fundamentals with the Chicago Board Options Exchange Market Volatility Index (VIX), a measure of the implied volatility of S\&P 500 index options, commonly called the "fear index". They find that a country's net foreign asset position, and, to a lesser extent, the size of the national stock market contribute to a currency's appreciation (vs. the USD) in times of financial stress. However, due to the unavailability of most of the supposed fundamental determinants at higher frequency, they make heavy use of data interpolation techniques (from annual to monthly frequency). This could be one of the reasons why their estimation results are somewhat imprecise and definitive conclusions are difficult to draw based on their analysis.

Besides that, Habib and Stracca do not provide an answer to the question, of whether currencies can be regarded as safe haven-currencies, but only to the question of what factors contribute to whether currencies appreciate or depreciate against the USD conditional on the level of financial stress. By providing an answer to the former question, we regard our work as being complementary to theirs. ${ }^{8}$ Using high-frequency data, Ranaldo and Söderlind (2010)

\footnotetext{
${ }^{6}$ According to Engel (2013) UIP fails to hold empirically for many currency pairs and time periods.

${ }^{7}$ Besides, our paper adds to the existing literature by, among others, Cappiello and De Santis (2005), as well as Hau and Rey $(2004,2006)$ on the relationship between exchange rate and stock market returns.

${ }^{8}$ Besides, our approach largely allows us to avoid the use of data interpolation techniques (see section 3 for details.)
} 
show that the CHF, EUR, JPY, and the GBP appreciate against the USD when the S\&P 500 exhibits negative returns, when US bond prices increase, and when currency market volatility rises. However, since fundamental data is not available at this frequency, other potential determinants are excluded from their analysis, potentially biasing their estimation results. By using monthly data, we are able to account for at least some of the classic exchange rate determinants in our analysis. Furthermore, by analyzing effective exchange rates, we avoid the issue that two "similar" safe haven currencies "cancel each other out" if one of them is denoted in the numerator and the other in the denominator of a bilateral exchange rate. Greenaway-McGrevy et al. (2012) perform a factor analysis of 23 nominal bilateral exchange rates. They find that three factors predict $80 \%$ of currency returns. Two of the identified factors are the JPY/USD and the CHF/USD exchange rate. While the conclusion that the market perception of these factors as safe haven currencies is the underlying driver would be speculative, it shows that these two currencies (JPY and CHF) obey some distinct pattern.

In their analysis of whether gold constitutes a safe haven asset, Baur and Lucey (2010) define a safe haven asset as "...an asset that is uncorrelated or negatively correlated with another asset or portfolio in times of market stress or turmoil." We slightly modify their definition, and define a safe haven currency in the following way: ${ }^{9}$

A safe haven currency is defined as a currency whose effective returns are negatively related to global stock market returns in times of high financial stress, even after controlling for the impact of carry trades (respectively, their reversal) and the possibly regime-specific impact of fundamental exchange rate determinants.

In contrast, $\ldots$

... a hedge currency is defined as a currency whose effective returns are negatively related to global stock market returns on average (i.e. unconditional on the stress-regime), even after controlling for the impact of carry trades (respectively, their reversal) and the impact of fundamental exchange rate determinants.

To get a first indication as to whether the empirical evidence might support the presence of safe haven currencies in line with our definition (which will be analyzed more carefully in the econometric analysis in section 3), figures 1 and 2 show scatter plots of effective G10-currency returns versus global stock market returns depending on whether financial stress is low (figure 1) or high (figure 2). ${ }^{10}$ At this point of the analysis, we (somewhat arbitrarily) define financial stress to be (comparably) low (high), if the CBOE S\&P 100 Volatility Index (VXO) is in its

\footnotetext{
${ }^{9}$ Baur and McDermott $(2010,2012)$ distinguish between a strong and and a weak safe haven asset, whereby the former is negatively, and the latter uncorrelated with the return of some reference asset.

${ }^{10}$ Figure 5 in the appendix additionally shows unconditional scatterplots of exchange rate returns vs. global stock market returns.
} 
lower $80 \%$ (upper 20\%) quantile, and disregard other exchange rate determinants. ${ }^{11}$ Since the axes are scaled differently in both graphs (for issues of visibility), table 1 additionally shows simple correlation coefficients between G10 currency returns and global stock market returns conditional on the VXO being in the respective quantile. For two out of the 10 currencies the CHF and the JPY - effective exchange rate returns are significantly negatively correlated with global stock market returns given that financial stress is in the highest quintile. For the EUR, the GBP and the USD, the correlations are also negative, albeit insignificantly. For all remaining currencies (AUD, CAD, NOK, NZF, SEK), the correlations are significantly positive in the high stress regime.

Figure 1: Effective exchange rate returns vs. global stock market returns if VXO in lower $80 \%$ quantile
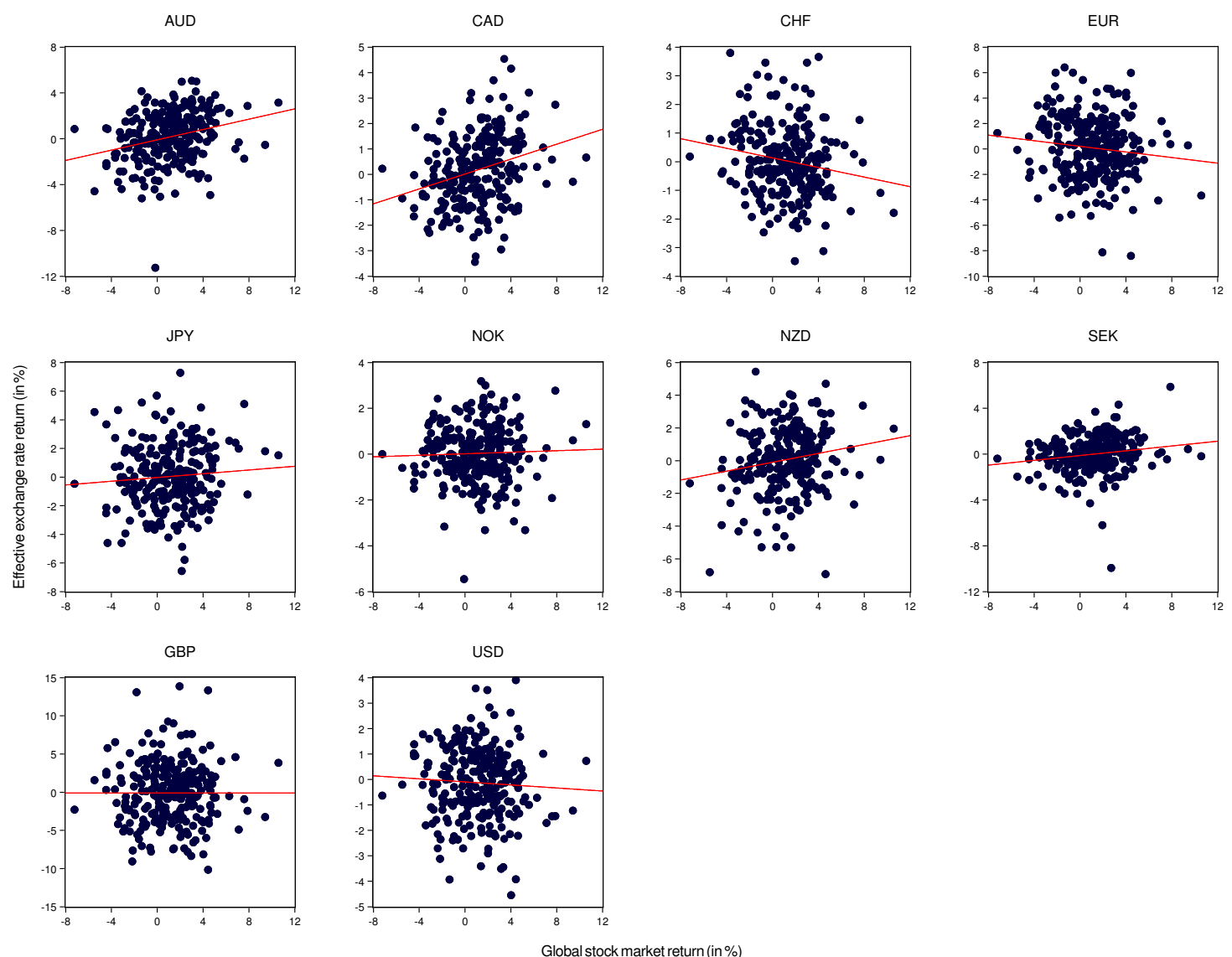

Brunnermeier et al. (2009) show that the skewness of bilateral exchange rate returns

\footnotetext{
${ }^{11}$ The VXO is chosen (as opposed to the more commonly used VIX) because it is available for the whole sample and because it is very highly correlated with the VIX (and, in fact, with a large number of other financial stress indicators) over the common sample.
} 
Figure 2: Effective exchange rate returns vs. global stock market returns if VXO in upper $20 \%$ quantile)
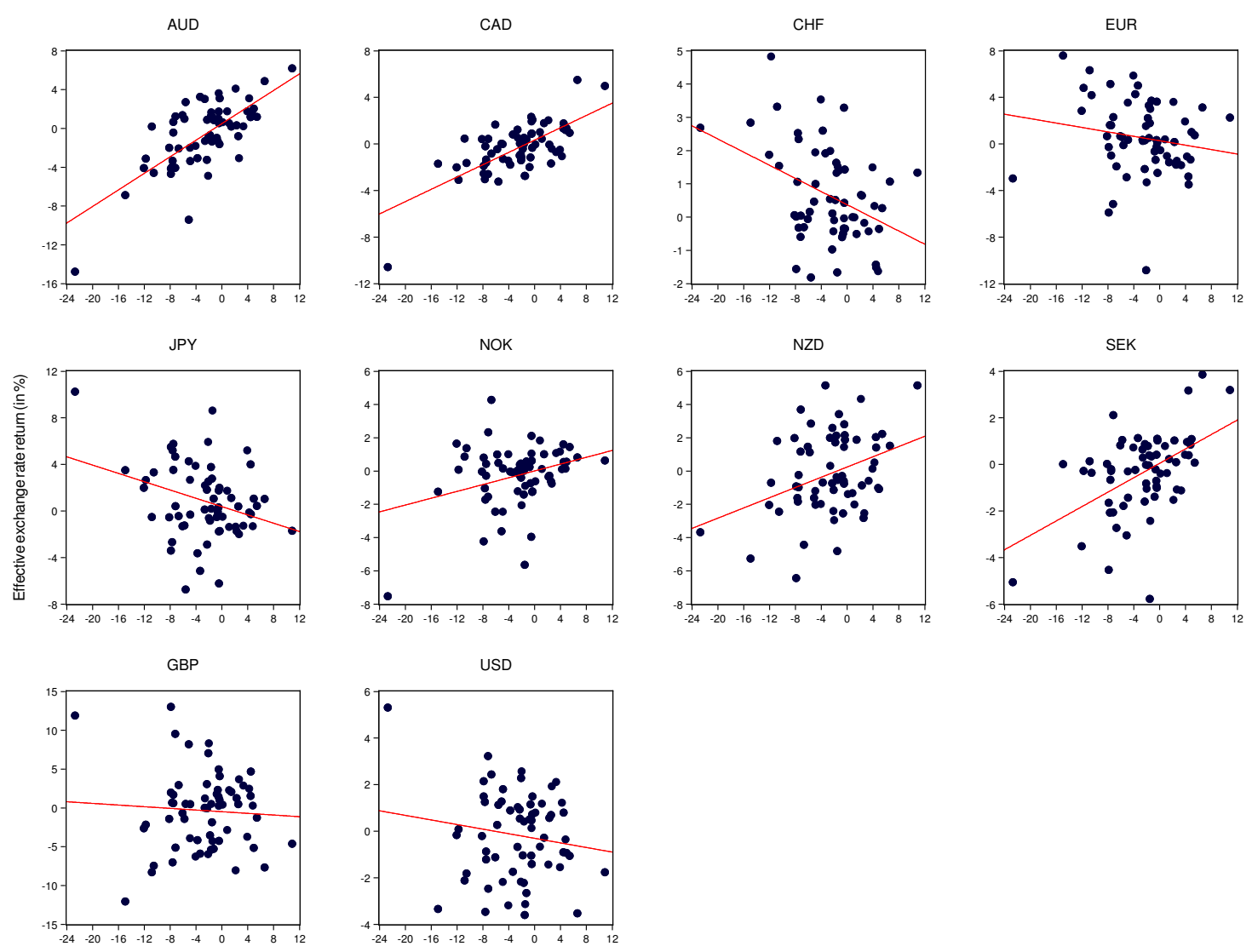

Global stock market return (in \%)

(against the USD) is positively related to the size of the interest differential of the respective country versus the US. ${ }^{12}$ It suggests that carry traders require a larger compensation (interest differential) for higher risk (skewness of exchange rate changes). To get some indication of whether their finding translates to effective exchange rates, figure 3 plots the empirical skewness of monthly effective exchange rate returns against the mean effective 1-month money market rate differentials (defined as the trade-weighted foreign rate minus the domestic rate) for the G10-currencies from 1986M3 to 2012M9 (respectively, 2011M8 for CHF). ${ }^{13}$ For three

\footnotetext{
${ }^{12}$ For further evidence, see Cazzaniga (2011).

${ }^{13}$ The sample for Switzerland ends one month prior to the announcement of the SNB to no longer tolerate a $\mathrm{CHF}$ /EUR exchange rate below the minimum rate of CHF 1.20. Since the weight of the bilateral EUR/CHFrate when calculating the effective $\mathrm{CHF}$ exchange rate is about $73 \%$, it is unsurprising that the unprecedented depreciation of the Swiss franc against the euro following immediately after the announcement, clearly impacts on the exchange rate in effective terms as well. Figure 4 in the appendix compares the empirical skewness of G10 effective exchange rates returns calculated for two different samples (1986M3 - 2012M9 vs. 1986M3
} 
Table 1: Correlations between currency returns and global stock market returns

\begin{tabular}{ccc}
\hline & $\begin{array}{c}\text { Lower 80\% } \\
\text { VXO-quantile }\end{array}$ & $\begin{array}{c}\text { Upper 20\% } \\
\text { VXO-quantile }\end{array}$ \\
\hline AUD & $0.27^{* * *}$ & $0.71^{* * *}$ \\
CAD & $0.28^{* * *}$ & $0.69^{* * *}$ \\
CHF & $-0.18^{* * *}$ & $-0.40^{* * *}$ \\
EUR & $-0.12^{* * *}$ & -0.17 \\
JPY & 0.08 & $-0.32^{* *}$ \\
NOK & 0.04 & $0.31^{* *}$ \\
NZD & $0.18^{* * *}$ & $0.36^{* * *}$ \\
SEK & $0.18^{* * *}$ & $0.50^{* * *}$ \\
GBP & -0.00 & -0.06 \\
USD & -0.06 & -0.15 \\
\hline
\end{tabular}

Note: Based on monthly data for the sample period from January 1986 to September 2012 (for CHF, to August 2011). For further details, see section $4 .{ }^{* * *}, * *$, and * denote significance levels of 1,5 , and $10 \%$, respectively.

of the G10 currencies - the CHF, the EUR, and the JPY - the distributions of currency returns are right-skewed, implying that large appreciations of these currencies occur more frequently than correspondingly large depreciations. This is consistent with these currencies serving as funding currencies, which appreciate abruptly and pronouncedly in times of crisis when carry trades are reversed, and/or them actually being safe haven currencies. ${ }^{14}$ However, the figure suggests that most currencies with domestic interest rates below the trade-weighted foreign rates have right-skewed distributions and vice versa (the only exceptions being the EUR and the GBP $).{ }^{15}$ The positive slope of the depicted OLS regression line indicates that the bilateral USD-based results by Brunnermeier et al. (2009) generalize to effective rates. From a different perspective, results by Clarida et al. (2009) suggest that the relationship between exchange rate returns and lagged interest differentials depend on the volatility regime: when volatility is in the top quartile, "Fama regressions" produce a (correctly signed) positive coefficient that is, however, larger than unity, whereas the coefficient is negative (and UIP clearly rejected) in the lowest quartile.

\footnotetext{
- 2011M8). It can be observed that the empirical skewness of effective CHF-returns changes markedly (even switches sign) after the SNB announcement, while the values are hardly affected by changing the sample in case of the other G10-currencies.

${ }^{14}$ The figure also shows that for the currencies, which are typically regarded as carry target currencies, the distributions of returns are left-skewed.

${ }^{15}$ In fact, the interest differential (defined as the weighted foreign rate minus the domestic rate), has been negative for the AUD and the NZD for $95 \%$, respectively $97 \%$ of the observations. In striking contrast, for the JPY and the CHF, the differential has been positive in about 1, respectively $4 \%$ of the cases only. For further evidence on the skewness of distributions of currency returns see Gagnon and Chaboud (2007).
} 
Figure 3: Skewness of effective exchange rate returns vs. mean effective interest differential

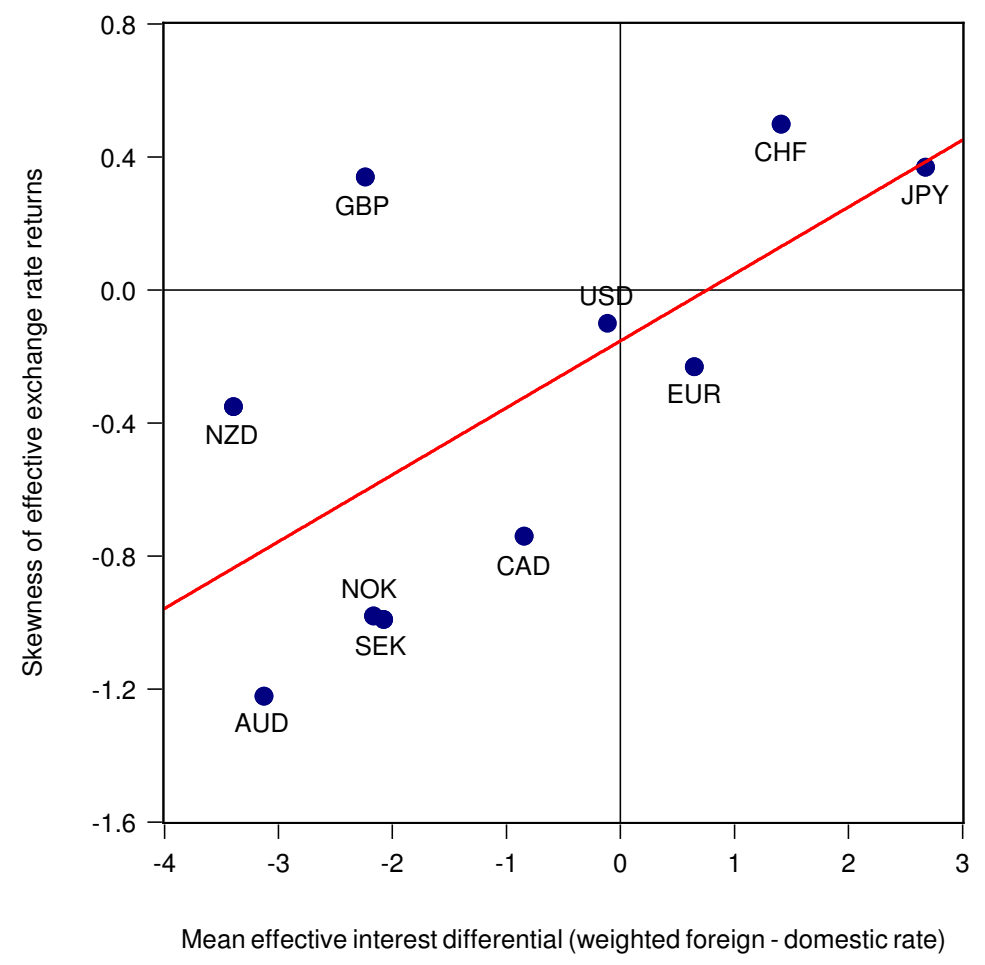

Summarizing, we observe that a number of currencies exhibit negative (unconditional) correlations between their returns and global stock market returns in times of high financial stress, and have positively skewed distributions of returns. Viewed in isolation, both patterns support the notion of these currencies as safe haven currencies. However, it is unclear, whether they are just artifacts of these currencies' role as carry funding currencies in tranquil times, whether they are due to other determinants which have been disregarded in the descriptive analysis so far, or whether they "survive" a more in-depth econometric analysis. Notwithstanding this, the evidence presented so far clearly supports a non-linear approach, in which the relationship between effective exchange rate returns and the supposed determinants is allowed to be regime-dependent. To this end, we set up a threshold-model, in which we condition on the level of financial stress, as measured by the VXO. In the following section, we describe the econometric model and the hypotheses tested. 


\section{Econometric model}

We implement the threshold regression approach of Hansen (2000). It allows the regression parameters to differ across regimes depending on the value of some threshold variable, in our case, the level of financial stress as measured by the VXO. However, for ease of exposition, we first present the linear regression model in equation 1 , to which the threshold regression model would collapse if the regression parameters were equal across regimes:

$$
\begin{aligned}
\Delta e_{t} & =\beta_{0}+\beta_{1}\left(i_{t-1}^{*}-i_{t-1}\right)+\beta_{2}\left(i_{t-1}^{*}-i_{t-1}\right) \cdot V X O_{t} \\
& +\beta_{3}\left(\pi_{t-1}^{*}-\pi_{t-1}\right)+\beta_{4} u_{t-1}+\beta_{5} \Delta m s c i w_{t}+\varepsilon_{t},
\end{aligned}
$$

where $\Delta e_{t}$ is the (effective) exchange rate return in period $t$ (in terms of foreign currency units per unit of domestic currency), $\left(i_{t-1}^{*}-i_{t-1}\right)$ the lagged (effective) interest differential, $V X O_{t}$ the CBOE S\&P 100 Volatility Index in period $t,\left(\pi_{t-1}^{*}-\pi_{t-1}\right)$ the lagged (effective) inflation differential, and $\Delta m s c i w_{t}$ the return on the MSCI world index in local currencies in period $t .{ }^{16}$ As a measure of broad stock market performance we alternatively considered the first principal component of the G10 countries' returns on their respective national MSCI index in local currency. Since the extracted first principal component from the G10 national indices and the MSCI world index returns are very highly correlated $(>0.95)$, we decided to use the MSCI world index return in the regression directly because of its straightforward interpretability. Foreign variables are denoted by an asterisk. Trade-weighted series are calculated as arithmetic/geometric averages of the respective G10 national series. The country-specific trade-weights used are presented in table 2 (official trade weights as used by the ECB rescaled so that they sum to one). Finally, $u_{t-1}$ denotes the deviation from trend-adjusted purchasing power parity (PPP) in $t-1$, where $u_{t}$ is obtained in two separate steps: first, we estimate the regression $q_{t}=\alpha_{0}+\alpha_{1}$ trend $+v_{t}$ over the sample from 1986M2 to 2012M9, where $q_{t}$ denotes the $\log$ CPI-based real effective exchange rate in period $t$, trend a deterministic time trend, and $v_{t}$ an iid error term. ${ }^{17}$ Based on this, we calculate $u_{t}=q_{t}-\hat{q}_{t}$.

Uncovered interest parity holds ex post (in strict form) if and only if $\beta_{1}=1$ and all other coefficient values equal zero. Error correction of the nominal effective exchange rate towards trend-adjusted PPP requires $\beta_{4}<0$. Relative PPP suggests that $\beta_{3}=1$. Lagged inflation rates are used in order to avoid violating the exogeneity assumption of the regressor, which,

\footnotetext{
${ }^{16}$ By using log exchange rates, we circumvent the Siegel paradox. Given this transformation, the depreciation/appreciation rate of the domestic currency is equal to the appreciation/depreciation rate of the foreign currency.

${ }^{17} \mathrm{~A}$ deterministic trend is allowed for in this regression because some of the currencies obey a trending pattern, and data on relative productivity developments, which could be the source of this behavior according to the productivity approach, are not available even for the G10 countries at the monthly frequency.
} 
Table 2: Weight matrix used for calculation of G10 effective exchange rates

\begin{tabular}{lrrrrrrrrrr}
\hline & AUD & CAD & CHF & EUR & JPY & NOK & NZD & SEK & GBP & USD \\
\hline AUD & 0.00 & 0.00 & 0.01 & 0.02 & 0.04 & 0.00 & 0.29 & 0.01 & 0.01 & 0.02 \\
CAD & 0.02 & 0.00 & 0.01 & 0.03 & 0.04 & 0.01 & 0.02 & 0.01 & 0.02 & 0.29 \\
CHF & 0.02 & 0.01 & 0.00 & 0.12 & 0.03 & 0.02 & 0.01 & 0.02 & 0.02 & 0.02 \\
EUR & 0.32 & 0.13 & 0.73 & 0.00 & 0.39 & 0.56 & 0.24 & 0.66 & 0.69 & 0.39 \\
JPY & 0.20 & 0.06 & 0.05 & 0.13 & 0.00 & 0.05 & 0.17 & 0.04 & 0.05 & 0.18 \\
NOK & 0.00 & 0.00 & 0.00 & 0.02 & 0.01 & 0.00 & 0.00 & 0.08 & 0.01 & 0.01 \\
NZD & 0.07 & 0.00 & 0.00 & 0.00 & 0.01 & 0.00 & 0.00 & 0.00 & 0.00 & 0.00 \\
SEK & 0.02 & 0.01 & 0.01 & 0.09 & 0.02 & 0.15 & 0.01 & 0.00 & 0.03 & 0.02 \\
GBP & 0.07 & 0.03 & 0.06 & 0.27 & 0.06 & 0.09 & 0.05 & 0.09 & 0.00 & 0.07 \\
USD & 0.27 & 0.75 & 0.12 & 0.31 & 0.42 & 0.10 & 0.20 & 0.09 & 0.16 & 0.00 \\
\hline
\end{tabular}

otherwise, could lead to a biased OLS estimator. We furthermore assume that the contemporaneous regressors $\left(V X O_{t}\right.$ and $\left.\Delta m s c i w_{t}\right)$ are exogenous. This assumption seems sensible because global stock market returns should contemporaneously not be too much affected by country-specific effective exchange rate changes. The same should hold for the VXO. The interaction term $\left(\left(i_{t-1}^{*}-i_{t-1}\right) \cdot V X O_{t}\right)$ is included in the model to control for the impact of carry trade reversals (at least approximately). ${ }^{18}$ Acknowledging the difficulties generally involved in measuring carry trades (see for instance Curcuru et al. (2011)), several pieces of evidence suggest that such a proxy is appropriate: Focusing on Japan, Hattori and Shin (2009) find that their preferred measure of carry trade activity, fluctuations in the size of the net interoffice accounts of foreign banks in Japan, is related to the state of overall risk appetite, as measured by the VIX, which itself is highly correlated with the VXO. ${ }^{19}$ Moreover, the use of the VXO is in line with the dominant part of the recent literature on carry trades which stresses the importance of market-wide distress (see Gyntelberg and Schrimpf (2011)). 1 month money market rates are used (as opposed to long term interest rates) because it is generally accepted that carry trades are concentrated in short-term instruments (see Gagnon and Chaboud (2007)).

Given the previous evidence on carry trades and their reversals, we expect $\beta_{2}>0$ for carry funding currencies. ${ }^{20}$ The parameter which is most interesting to us is $\beta_{5}$. If $\beta_{5}$ is significantly negative (positive), it implies that the respective currency qualifies as a hedge (speculative) currency according to our definition in section 2 .

If we allow the regression parameters to differ between two regimes, the threshold model representation of model (1) is:

\footnotetext{
${ }^{18}$ A similar proxy is used by Habib and Stracca (2012).

${ }^{19}$ Unfortunately, the size of net interoffice accounts of foreign banks is not available for all G10 countries.

${ }^{20}$ If not for the full sample, the respective coefficient should at least be positive in the high stress regime, i.e. $\beta_{h, 2}>0$ in equation 2 .
} 


$$
\begin{aligned}
\Delta e_{t} & =\beta_{s, 0}+\beta_{s, 1}\left(i_{t-1}^{*}-i_{t-1}\right)+\beta_{s, 2}\left(i_{t-1}^{*}-i_{t-1}\right) \cdot V X O_{t} \\
& +\beta_{s, 3}\left(\pi_{t-1}^{*}-\pi_{t-1}\right)+\beta_{s, 4} u_{t-1}+\beta_{s, 5} \Delta m s c i w_{t}+\varepsilon_{t}
\end{aligned}
$$

where

$$
s=\left\{\begin{array}{l}
l \text { if } V X O_{t} \leq \gamma \\
h \text { if } V X O_{t}>\gamma
\end{array}\right.
$$

$\beta_{s, i}$ denote the regime-specific regression parameters, $\gamma$ the threshold value (in our case, the value of the $V X O)$, which splits the sample into two regimes, $l$ and $h$ are acronyms ( $l=$ low, $h=$ high) used to denote the specific stress-regime, $s$. In line with our definition of a safe haven currency provided in section 2, a currency will be classified as a safe haven currency if and only if $\hat{\beta}_{h, 5}<0$. An overview of the conditions which need to be fulfilled in order for a currency to qualify as a hedge, safe haven, carry funding, or speculative currency is provided in table 3.

The threshold model (2) can be easily written in compact form as a single equation with the help of an indicator function, which allocates the observations to the two regimes. Then, it can be estimated by concentrated OLS. Thereby, it is made use of the fact that, conditional on $\gamma$, the model is linear in the coefficients. The estimate $\hat{\gamma}$ is the value of the $V X O$ that minimizes the sum of squared errors function across both regimes. Once the threshold-value is determined (i.e. $\gamma$ is "concentrated out"), the regression parameters can be easily obtained by OLS. Then, a likelihood ratio test is performed to test the significance of the threshold (i.e. to test $H_{0}: \gamma=\gamma_{0}$ ). Because heteroscedasticity is suspected, heteroscedasticity-robust $p$-values are obtained via bootstrapping (using 1000 replications).

Table 3: Currency classification: hypothesized coefficient signs

\begin{tabular}{rcccc}
\hline & $\beta_{2}$ & $\beta_{h, 2}$ & $\beta_{5}$ & $\beta_{h, 5}$ \\
\hline $\begin{array}{r}\text { hedge } \\
\text { safe haven }\end{array}$ & & & & \\
$\begin{array}{r}\text { carry funding } \\
\text { speculative }\end{array}$ & + & + & & \\
\hline
\end{tabular}

Note: A currency is classified as a carry funding vehicle if $\beta_{2}>0$ (one regimecurrencies) or $\beta_{h, 2}>0$ (two regimecurrencies). 


\section{Data and Estimation Results}

The sample period is from January 1986 to September 2012. Monthly average USD-based nominal exchange rates (used to construct the effective exchange rates) are obtained from IMF International Financial Statistics (IMF IFS). CPI data are obtained from Bundesbank and IMF IFS. For Australia and New Zealand, quarterly CPI series had to be interpolated to a monthly frequency. Data on the VXO, LIBOR 1 month money market rates (monthly average) and MSCI world index returns in local currencies have been obtained from Datastream. In instances when LIBOR rates are not available for the full sample, we update them backwards using the growth rates of highly correlated short term interest rates obtained from national sources. Euro area data are merged with German data prior to the introduction of the EUR (using the irrevocably fixed D-Mark/EUR-conversion rate and the growth rates of the German equivalents to the other Euro area series). ${ }^{21}$

Table 4: Tests for sample split and estimated threshold values

\begin{tabular}{rcl}
\hline & $\hat{\gamma}$ & $L R_{n}(\hat{\gamma})$ \\
\hline AUD & 23.56 & $15.99^{*}$ \\
CAD & 20.48 & 12.50 \\
CHF & 26.11 & $15.90^{*}$ \\
EUR & 16.67 & 11.78 \\
JPY & 24.89 & $16.59^{*}$ \\
NOK & 20.47 & 15.05 \\
NZD & 19.43 & 14.24 \\
SEK & 31.36 & 8.77 \\
GBP & 16.15 & $17.81^{* *}$ \\
USD & 19.75 & $17.27^{*}$ \\
\hline
\end{tabular}

Note: $* * *, * *, *$ indicate significance of the estimated threshold at the 1,5 , respectively $10 \%$ significance level.

The threshold test results are presented in table 4. For five of the G10 currencies (AUD, CHF, JPY, GBP, and USD), the results point towards the existence of two distinct regimes. Unsurprisingly, the endogenously determined VXO-threshold levels differ among currencies. The threshold-levels are highest for the JPY $(\mathrm{VXO}=24.89)$ and the CHF $(\mathrm{VXO}=26.11)$. The levels imply that about $25 \%$, respectively $20 \%$ of the observations fall into the high-stress regime for these two currencies. For the CAD, the EUR, the NOK, the NZD, and the SEK, the relationship between effective exchange rate returns and the included determinants is not regime-dependent over the sample period.

\footnotetext{
${ }^{21}$ Details are available on request.
} 
Estimation results for the two-regime currencies are presented in table 5, and those for the one regime-currencies in table 6 . In order not to distract from the main message of this paper, our interpretation of the results focuses on the estimates of $\beta_{5}$, respectively $\beta_{s, 5}$. However, we will also comment on other coefficient estimates whenever they contain useful information to appropriately classify the currencies. As indicated previously, we classify a currency as a hedge currency if $\beta_{5}<0$, and as a safe haven currency if $\beta_{h, 5}<0$. Of course, a currency may well be both, a hedge as well as a safe haven currency according to these definitions.

According to the estimation results, two currencies qualify as safe haven currencies, the USD and the CHF. The results for the CHF are particularly striking. In the low stress-regime, CHF effective exchange rate returns can be described as largely fundamentals-determined; for instance, relative PPP cannot be rejected in this regime. In the high stress-regime, the coefficients of all fundamental determinants turn individually insignificant. The only remaining variable with a significant impact on CHF currency returns are global stock market returns. On average, a 1 percentage point (pp) increase (decrease) in global stock market returns is associated with 0.12 pp decrease (increase) in CHF returns. Although global stock market returns also matter for CHF returns in the low stress-regime, the absolute value of the estimated coefficient of -0.05 is considerably lower, and only significant at the $10 \%$ level (as opposed to $1 \%$ in the high stress-regime). If we only allow for one regime, the estimated coefficient value is about -0.09. Together, these results imply that the CHF is both a hedge as well as a safe haven currency. Furthermore, we observe that even if only global stock market returns seem to matter in the high stress-regime, the explanatory power of the model increases considerably from the low to the high stress-regime. In the low stress-regime just around $13 \%$ of CHF returns can be explained by the model, while around $37 \%$ of its returns can be explained by the model if the VXO is above its threshold value of 26.11. In contrast to the CHF, the USD can be classified as a safe haven currency only because USD returns are significantly negatively related to global stock market returns in the high stress-regime, but unrelated to global stock market returns on average. However, the intensity of the safe haven effect is considerably smaller for the USD than for the CHF (-0.054 compared to -0.120). Two other results are noteworthy. First, we observe significant error-correction of the USD towards trend-adjusted PPP in the low stress-regime, which vanishes in the high stress-regime. Second, the sign, size and significance of the carry trade interaction term coefficient suggests that carry trades in which the USD serves as a funding currency are unwound in times of high financial stress.

Regarding the JPY, we observe that once we control for other fundamental exchange rate determinants, its returns appear unrelated to global stock market returns, both in times of low and high financial stress, implying that the JPY neither qualifies as a safe haven currency nor as a hedge currency according to our definition. The estimation results are supportive of its widely discussed role as a carry funding currency: the negative sign of $\hat{\beta}_{l, 1}$ is at odds with the UIP condition and in line with the role of the JPY to fund carry trades if financial 
Table 5: Estimation results for two regime-currencies (continued on next page)

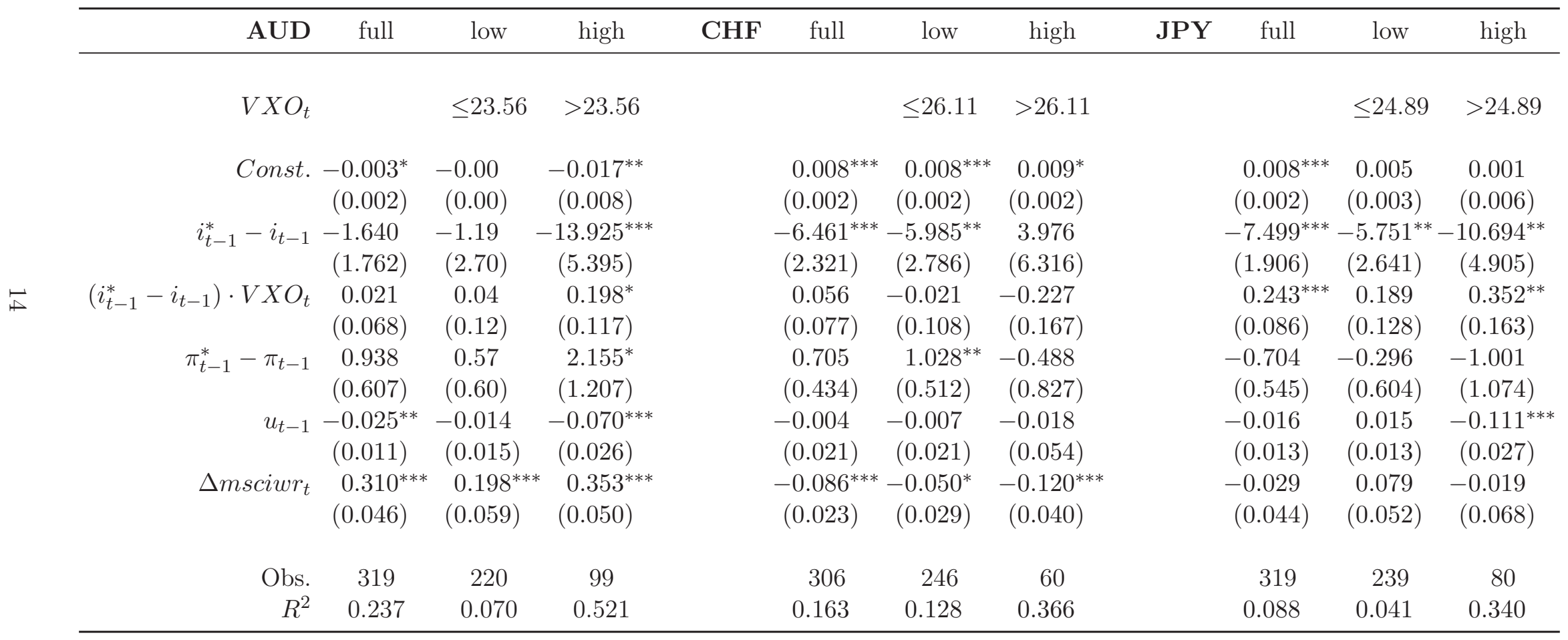


Table 5 contd

\begin{tabular}{|c|c|c|c|c|c|c|c|}
\hline GBP & full & low & high & USD & full & low & high \\
\hline$V X O_{t}$ & & $\leq 16.15$ & $>16.15$ & & & $\leq 19.75$ & $>19.75$ \\
\hline Const. & $\begin{array}{c}0.003 \\
(0.004)\end{array}$ & $\begin{array}{c}-0.008 \\
(0.006)\end{array}$ & $\begin{array}{l}0.013^{* * *} \\
(0.005)\end{array}$ & & $\begin{array}{c}-0.002 \\
(0.001)\end{array}$ & $\begin{array}{c}-0.003^{* *} \\
(0.001)\end{array}$ & $\begin{array}{c}-0.004^{* *} \\
(0.002)\end{array}$ \\
\hline$i_{t-1}^{*}-i_{t-1}$ & $\begin{array}{c}-1.904 \\
(4.205)\end{array}$ & $\begin{array}{c}-20.899 \\
(24.060)\end{array}$ & $\begin{array}{c}-4.507 \\
(4.701)\end{array}$ & & $\begin{array}{c}-1.264 \\
(2.127)\end{array}$ & $\begin{array}{c}-3.370 \\
(4.221)\end{array}$ & $\begin{array}{c}-18.066^{* * *} \\
(5.156)\end{array}$ \\
\hline$\left(i_{t-1}^{*}-i_{t-1}\right) \cdot V X O_{t}$ & $\begin{array}{c}0.173 \\
(0.177)\end{array}$ & $\begin{array}{c}1.912 \\
(1.687)\end{array}$ & $\begin{array}{r}0.369^{*} \\
(0.198)\end{array}$ & & $\begin{array}{c}-0.003 \\
(0.111)\end{array}$ & $\begin{array}{c}0.183 \\
(0.281)\end{array}$ & $\begin{array}{l}0.566^{* * *} \\
(0.196)\end{array}$ \\
\hline$\pi_{t-1}^{*}-\pi_{t-1}$ & $\begin{array}{r}1.625^{*} \\
(0.954)\end{array}$ & $\begin{array}{c}3.345^{* *} \\
(1.541)\end{array}$ & $\begin{array}{r}1.896^{*} \\
(1.138)\end{array}$ & & $\begin{array}{c}-0.281 \\
(0.519)\end{array}$ & $\begin{array}{c}0.293 \\
(0.627)\end{array}$ & $\begin{array}{c}-0.957 \\
(0.778)\end{array}$ \\
\hline$u_{t-1}$ & $\begin{array}{c}-0.034^{* *} \\
(0.013)\end{array}$ & $\begin{array}{c}-0.069 \\
(0.044)\end{array}$ & $\begin{array}{c}-0.047^{* * *} \\
(0.015)\end{array}$ & & $\begin{array}{c}-0.021^{* *} \\
(0.009)\end{array}$ & $\begin{array}{c}-0.052^{* * *} \\
(0.017)\end{array}$ & $\begin{array}{r}-0.015 \\
(0.011)\end{array}$ \\
\hline$\Delta m s c i w r_{t}$ & $\begin{array}{c}-0.044 \\
(0.089)\end{array}$ & $\begin{array}{c}0.213 \\
(0.238)\end{array}$ & $\begin{array}{c}-0.067 \\
(0.093)\end{array}$ & & $\begin{array}{c}-0.037 \\
(0.035)\end{array}$ & $\begin{array}{c}0.004 \\
(0.056)\end{array}$ & $\begin{array}{r}-0.054^{*} \\
(0.033)\end{array}$ \\
\hline $\begin{array}{r}\text { Obs. } \\
R^{2}\end{array}$ & $\begin{array}{c}319 \\
0.041\end{array}$ & $\begin{array}{c}91 \\
0.114\end{array}$ & $\begin{array}{c}228 \\
0.085\end{array}$ & & $\begin{array}{c}319 \\
0.041\end{array}$ & $\begin{array}{c}159 \\
0.071\end{array}$ & $\begin{array}{c}160 \\
0.150\end{array}$ \\
\hline
\end{tabular}

Note: ${ }^{* * *}, * *$, and ${ }^{*}$ denote significance levels of 1,5 , or $10 \%$, respectively, based on robust standard errors. 
Table 6: Estimation results for one regime-currencies

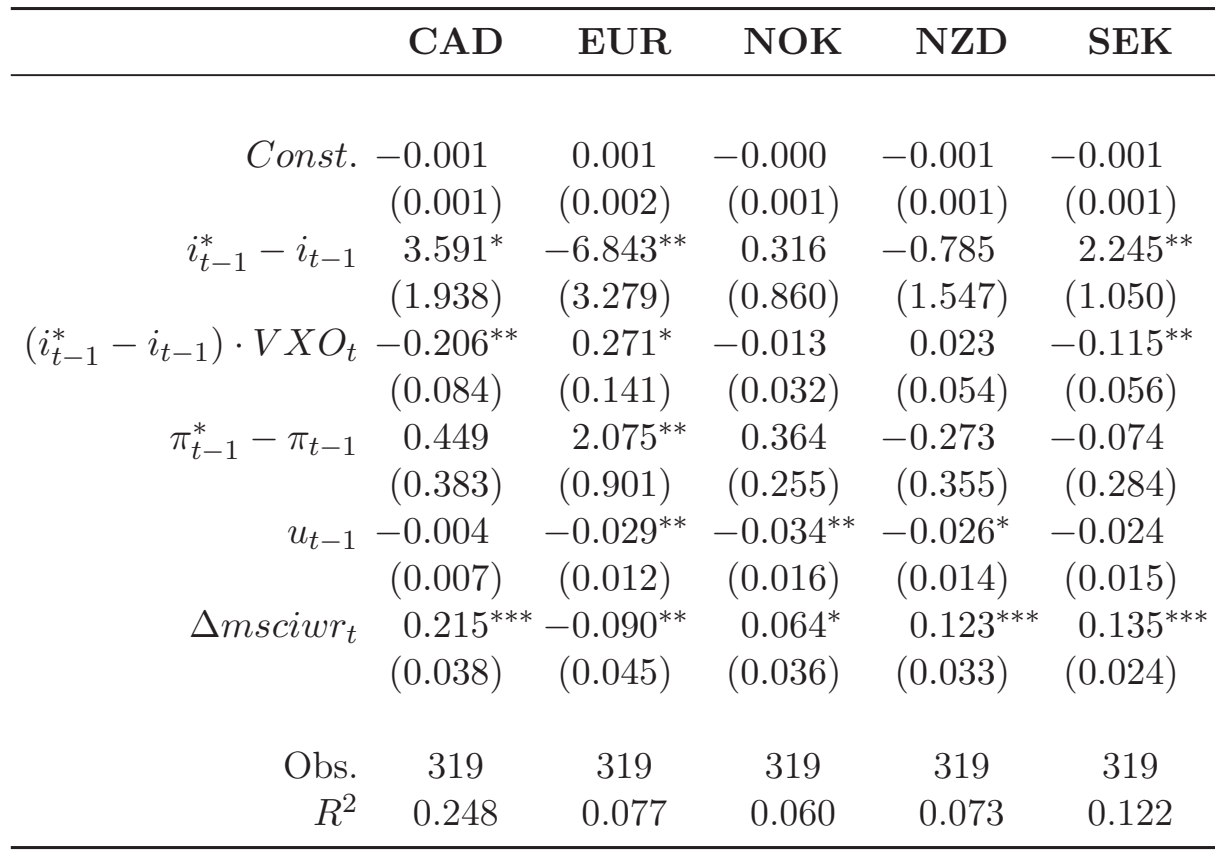

Note: $* * *, * *$, and ${ }^{*}$ denote significance levels of 1,5 , or $10 \%$, respectively, based on robust standard errors.

stress is low ("carry funding regime"), while $\hat{\beta}_{h, 2}>0$ suggests that carry trades are unwound in times of high financial stress ("carry unwinding regime") exerting upward pressure on the Japanese currency.

The EUR qualifies as a hedge currency according to the estimation results. On average, a $1 \mathrm{pp}$ increase (decrease) in global stock market returns is associated with a $0.09 \mathrm{pp}$ decrease (increase) in effective EUR returns. Furthermore, the estimation results suggest significant error correction of the EUR towards trend-adjusted long run PPP. Since the EUR has been at the center of interest during the Euro area sovereign debt crisis in recent years, further estimation results for bilateral EUR-based G9-exchange rates are presented in tables 9 (tworegime cases) and 10 (one-regime cases) in the appendix. The results coincide with anecdotal evidence that the CHF does indeed act as a safe haven currency relative to the EUR. However, none of the other G9-currencies serves as a safe haven or hedge currency relative to the EUR. Regarding the USD/EUR-exchange rate, we find no evidence for a significant threshold effect related to the level of financial stress. We therefore only estimate the model for the single regime-case. In this single regime, the USD/EUR-exchange rate and global stock market returns are not significantly related. The estimation results furthermore suggest that the EUR serves as a safe haven currency relative to the CAD, NOK and SEK, and as a hedge currency relative to the AUD and NZD. The fact that we do not find evidence for a significant threshold for the effective EUR-exchange rate, but find such evidence for a number of bilateral rates, shows the importance of using effective rates when assessing a currency's overall safe 
haven status and the impact of such a status on the international price competitiveness of the respective economy.

Due to space limitations, we restricted the description of the estimation results above to a subset of the G10-currencies. Therefore, table 7 additionally provides a stylized classification of all G10-currencies (including those not explicitly described in this section) based on the estimation results and our previously described classification criteria. ${ }^{22}$

Table 7: Stylized classification of G10 currencies

\begin{tabular}{ccccc}
\hline & 2-regimes & 1 regime & Currency Classification \\
\hline & Low & High & Overall & \\
& $\hat{\beta}_{l, 5}$ & $\hat{\beta}_{h, 5}$ & $\hat{\beta}_{5}$ & Speculative $^{* * *}$ \\
AUD & + & + & + & Speculative $^{* * *}$ \\
CAD & & & + & Hedge $^{* * *} /$ Safe Haven $^{* * *}$ \\
CHF & - & - & - & Hedge $^{* *}$ \\
EUR & & & - & Carry Funding $^{* * *}$ \\
JPY & 0 & 0 & 0 & Speculative $^{* *}$ \\
NOK & & & + & Speculative $^{* * *}$ \\
NZD & & & + & Speculative $^{* * *}$ \\
SEK & & & + & Unclear $^{* * *} /$ Safe Haven $^{*}$ \\
GBP & 0 & 0 & 0 & Carry Funding \\
USD & 0 & - & 0 & Funding \\
\hline
\end{tabular}

Note: In this table, we focus on the most distinct characteristics of the various currencies based on the estimation results. Further details are provided in section 4 and in tables $5-6$. ***,**, and * denote whether the estimated coefficients on which the classifications are based are individually significant at the 1, 5, or $10 \%$ level, respectively. A "+"("-") indicates that a particular estimated coefficient is positive (negative) and significantly different from zero at the $10 \%$ level. A " 0 " indicates that the estimated coefficient does not differ from zero significantly.

One drawback of the preceding analysis, in which we have allowed for country- (or exchange rate-) specific threshold levels, is that results are somewhat difficult to compare to each other across countries because the determined threshold levels differ. Therefore, table 8 additionally presents estimates of $\beta_{s, 5}$ for various VXO-quantiles set in ad-hoc fashion, which can be compared to the ones presented in table 5 and table 6 . Results are presented for the lower (upper) $70(30), 80(20)$, and 90 (10)\% quantiles of the VXO. Since the same VXO-levels are used to split the samples into low- and high-stress regimes for all currencies, coefficient estimates can be easily compared across currencies. Since some of the endogenously selected threshold-values are comparatively low (most notably, for the GBP), these estimation results furthermore allow us to check whether the previous results of the estimations in which the stress-regimes have been determined endogenously, transfer to more extreme levels of financial

\footnotetext{
${ }^{22}$ Only for the GBP, the estimation results do not allow a clear classification.
} 
stress. To obtain the coefficient estimates in table 8, model 1 has been re-estimated for each currency and each of the selected VXO-quantiles, conditional on the VXO being in the respective quantile. The table also depicts regime-specific estimation results for those currencies, for which no significant threshold effect has been detected.

Several results stand out. First, for most of the G10-currencies, the previous classifications do not change once we redefine the threshold values. The AUD, the CAD, the NZD, and the SEK can still be regarded as speculative currencies. However, for most of these currencies, the estimated elasticities between exchange rate and global stock market returns (moderately) increase if we reduce the size of the upper quantile (i.e. once we move from the $30 \%$ towards the $10 \%$ upper quantile of the VXO). On the other side of the spectrum, the CHF is still classified as a safe haven and a hedge currency. Additionally, the point estimates for $\beta_{h, 5}$ are remarkably stable for this currency. The same holds for the classifications of the GBP and the JPY, which do not obey (significant) safe haven characteristics according to the estimates for any of the selected upper quantiles. In contrast, for the EUR and the USD, results differ somewhat across the various quantiles. For the EUR, the absolute size of $\hat{\beta}_{h, 5}$ gets smaller once we move from the upper $30 \%$ to the upper $10 \%$ quantile. The estimated elasticity remains negative, however (albeit insignificantly). Therefore, the results signal that the strength of the euro's property as a hedge diminishes once we move to more extreme VXO-values. Regarding the USD, the sign of $\hat{\beta}_{h, 5}$ is negative for all three upper quantiles, albeit not significantly, supporting our previous assessment that the case for the CHF being a safe haven currency is much stronger than for the USD. 
Table 8: Estimates of $\beta_{5}$ conditional on different VXO levels

\begin{tabular}{|c|c|c|c|c|c|c|c|c|c|c|}
\hline & AUD & CAD & CHF & EUR & JPY & NOK & NZD & SEK & GBP & USD \\
\hline Full sample & $0.31^{* * *}$ & $0.22^{* * *}$ & $-0.09^{* * *}$ & $-0.09^{*}$ & -0.03 & $0.06^{*}$ & $0.12^{* * *}$ & $0.13^{* * *}$ & -0.05 & -0.04 \\
\hline Below threshold & $0.20^{* * *}$ & & $-0.05^{*}$ & & 0.08 & & & & 0.21 & 0.00 \\
\hline Above threshold & $0.35^{* * *}$ & & $-0.12^{* * *}$ & & -0.02 & & & & -0.07 & $-0.05^{*}$ \\
\hline \multicolumn{11}{|l|}{$\%$ quantile of $\mathrm{VXO}$} \\
\hline lower 70 & $0.19^{* * *}$ & $0.15^{* * *}$ & -0.03 & -0.07 & 0.09 & 0.01 & 0.08 & $0.09^{* *}$ & -0.06 & $-0.07^{*}$ \\
\hline upper 30 & $0.35^{* * *}$ & $0.25^{* * *}$ & $-0.11^{* * *}$ & $-0.11^{*}$ & -0.02 & 0.06 & $0.15^{* * *}$ & $0.15^{* * *}$ & -0.02 & -0.05 \\
\hline lower 80 & $0.22^{* * *}$ & $0.15^{* * *}$ & $-0.05^{*}$ & $-0.10^{*}$ & 0.07 & 0.02 & $0.13^{* * *}$ & $0.09^{* *}$ & 0.02 & -0.04 \\
\hline upper 20 & $0.38^{* * *}$ & $0.27^{* * *}$ & $-0.12^{* * *}$ & -0.06 & -0.04 & 0.03 & $0.14^{* * *}$ & $0.15^{* * *}$ & -0.09 & -0.05 \\
\hline lower 90 & $0.22^{* * *}$ & $0.15^{* * *}$ & $-0.08^{* * *}$ & $-0.13^{* *}$ & 0.02 & 0.03 & $0.07^{*}$ & $0.08^{* * *}$ & 0.03 & -0.02 \\
\hline upper 10 & $0.45^{* * *}$ & $0.32^{* * *}$ & $-0.13^{* * *}$ & -0.03 & -0.08 & 0.04 & $0.18^{* *}$ & $0.16^{* * *}$ & -0.16 & -0.07 \\
\hline
\end{tabular}

Note: For each currency and each specified quantile of the VXO, model 1 has been re-estimated conditional on the VXO being in the respective quantile. Here, only the VXO-quantile-specific estimates of $\beta_{5}$ are provided. Estimation results for the other coefficients are available upon request. $* * *, * *$, and $*$ denote significance levels of 1,5 , and $10 \%$, respectively, based on robust standard errors. 


\section{Conclusions}

In this paper, we analyze which of the G10 currencies really qualify as safe haven currencies. To this end, we follow a threshold regression approach, where G10 effective exchange rate returns are regressed on a set of fundamental determinants as well as on global stock market returns. The VXO, a proxy for the level of financial stress, is used as the threshold variable. The use of effective exchange rate returns (as opposed to bilateral returns) allows us to gauge whether a certain currency can be regarded as a safe haven currency in absolute terms, which is what we really think of when speaking of a "safe haven currency". As a further benefit, our analysis of effective exchange rates considerably mitigates the problem inherent in previous studies that two similar safe haven currencies "cancel each other out" in the numerator and the denominator of a bilateral exchange rate.

Our results suggest that the CHF clearly qualifies as a safe haven currency since its returns are negatively related to global stock market returns (our preferred reference portfolio) in times of high financial stress. However, at the same time, it is also a hedge currency since the relation between its currency and global stock market returns is also negative on average (i.e. unconditional on the level of financial stress). While the CHF is largely determined by "traditional" exchange rate fundamentals in times of low financial stress, global stock market returns are the only variable exerting a statistically significant impact on CHF returns in times of high financial stress. The evidence furthermore suggests that the USD can be regarded as a safe haven currency, although less clearly. The JPY, often described as a safe haven currency in the financial press, should instead be regarded as a carry funding currency, which appreciates in times of crisis because carry trades are reversed. For the EUR, we do not find evidence for a threshold effect related to the level of financial stress when analyzing effective returns. Moreover, an in-depth analysis of bilateral EUR exchange rate returns suggests that only the CHF qualifies as a safe haven currency relative to the EUR. Somewhat at odds with statements in the financial press in the course of the Euro area sovereign debt crisis, our results do not point towards a distinct pattern of USD/EUR returns in episodes of high financial stress. 


\section{References}

Baur, D. and Lucey, B. (2010) Is gold a hedge or a safe haven? An analysis of stocks, bonds and gold, Financial Review, 45, 217-229.

Baur, D. G. and McDermott, T. K. (2010) Is gold a safe haven? International evidence, Journal of Banking 63 Finance, 34, 1886-1898.

Baur, D. G. and McDermott, T. K. (2012) Safe haven assets and investor behaviour under uncertainty, The Institute for International Integration Studies Discussion Paper 392.

Brunnermeier, M. K., Nagel, S. and Pedersen, L. H. (2009) Carry trades and currency crashes, in NBER Macroeconomics Annual 2008, Volume 23, University of Chicago Press, pp. 313347.

Burnside, C., Eichenbaum, M. and Rebelo, S. (2011) Carry trade and momentum in currency markets, Annual Review of Financial Economics, 3, 511-535.

Cappiello, L. and De Santis, R. A. (2005) Explaining exchange rate dynamics: The uncovered equity return parity condition, ECB Working Paper 529.

Cazzaniga, S. (2011) Crash risk in currency markets - a skewness measure approach, Swiss Finance Institute Research Paper 11-61.

Cheung, Y.-W., Chinn, M. D. and Fujii, E. (2007) The overvaluation of renminbi undervaluation, Journal of International Money and Finance, 26, 762-785.

Chinn, M. and Meredith, G. (2005) Testing uncovered interest parity at short and long horizons during the post-Bretton Woods era, NBER Working Paper 11077.

Clarida, R., Davis, J. and Pedersen, N. (2009) Currency carry trade regimes: Beyond the Fama regression, Journal of International Money and Finance, 28, 1375-1389.

Curcuru, S., Vega, C. and Hoek, J. (2011) Measuring carry trade activity, in Proceedings of the IFC Conference on "Initiatives to address data gaps revealed by the financial crisis, Basel, 25-26 August 2010", Bank for International Settlements, vol. 34, pp. 436-453.

Engel, C. (2013) Exchange rates and interest parity, NBER Working Paper 19336.

Froot, K. A. and Thaler, R. H. (1990) Anomalies: Foreign exchange, The Journal of Economic Perspectives, 4, 179-192.

Gagnon, J. E. and Chaboud, A. P. (2007) What can the data tell us about carry trades in Japanese yen?, International Finance Discussion Paper 899, Board of Governors of the Federal Reserve System (U.S.). 
Greenaway-McGrevy, R., Mark, N. C., Sul, D. and Wu, J.-L. (2012) Exchange rates as exchange rate common factors, Hong Kong Institute for Monetary Research Working Paper 21.

Gyntelberg, J. and Schrimpf, A. (2011) FX strategies in periods of distress, BIS Quarterly Review 12.

Habib, M. M. and Stracca, L. (2012) Getting beyond carry trade: What makes a safe haven currency?, Journal of International Economics, 87, 50-64.

Hansen, B. (2000) Sample splitting and threshold estimation, Econometrica, 68, 575-603.

Hattori, M. and Shin, H. S. (2009) Yen carry trade and the subprime crisis, IMF Staff Paper, 56, 384-409.

Hau, H. and Rey, H. (2004) Can portfolio rebalancing explain the dynamics of equity returns, equity flows, and exchange rates?, The American Economic Review, 94, 126-133.

Hau, H. and Rey, H. (2006) Exchange rates, equity prices, and capital flows, Review of Financial Studies, 19, 273-317.

Mehl, A. and Cappiello, L. (2009) Uncovered interest parity at long horizons: Evidence on emerging economies, Review of International Economics, 17, 1019-1037.

Ranaldo, A. and Söderlind, P. (2010) Safe haven currencies, Review of Finance, 14, 385-407. 


\section{A Appendix}

Figure 4: Skewness of G10 effective exchange rate returns
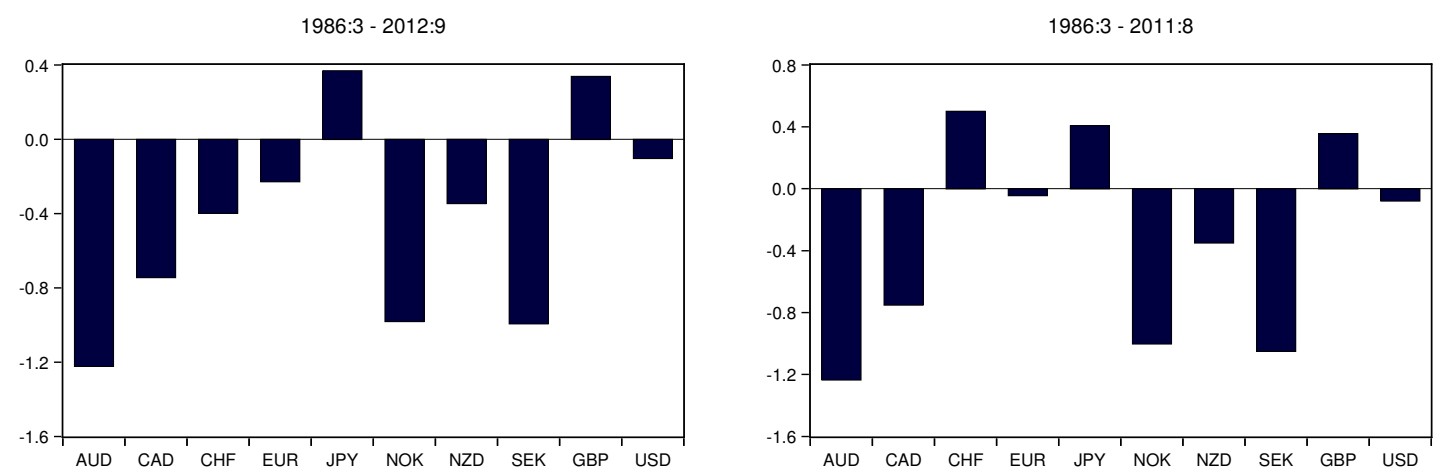

Note: An increase of the underlying nominal effective exchange rate index implies an appreciation of the domestic currency. A positive bar therefore indicates that large appreciations of the respective currency occur more frequently than correspondingly large depreciations. 
Figure 5: Effective exchange rate returns vs. global stock market returns
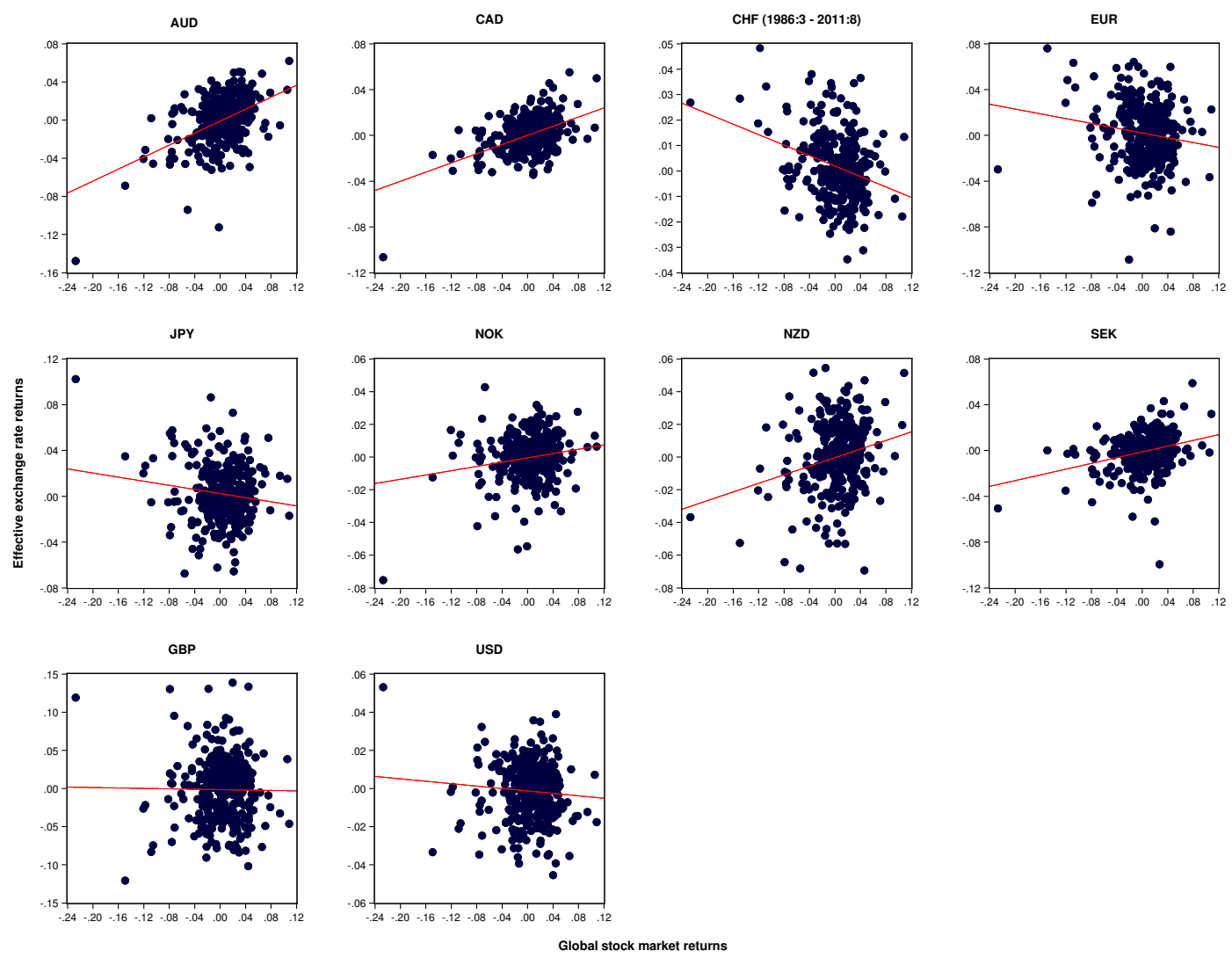
Table 9: Estimation results for bilateral EUR-based exchange rates with two regimes (continued on next page)

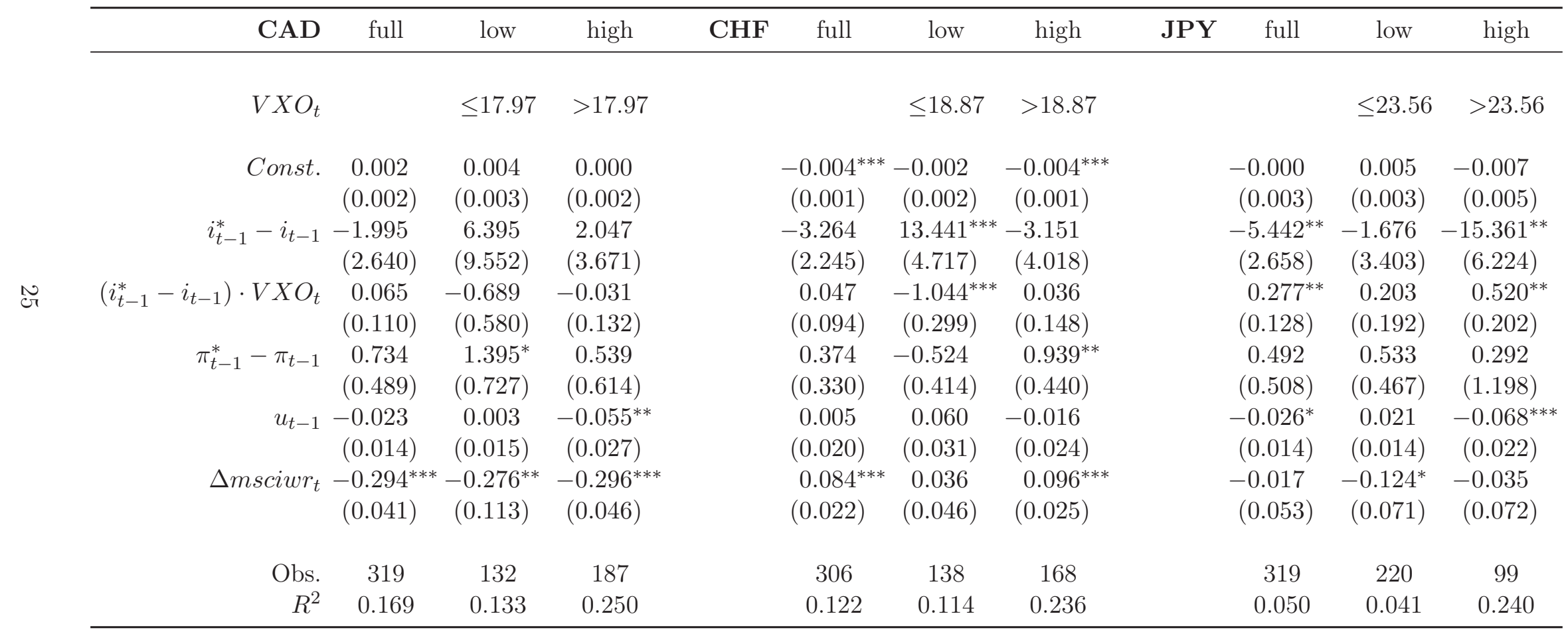


Table 9 contd.

\begin{tabular}{|c|c|c|c|c|c|c|c|c|c|c|c|}
\hline NOK & full & low & high & SEK & full & low & high & GBP & full & low & high \\
\hline$V X O_{t}$ & & $\leq 22.90$ & $>22.90$ & & & $\leq 14.96$ & $>14.96$ & & & $\leq 17.90$ & $>17.90$ \\
\hline Const. & $\begin{array}{c}0.002 \\
(0.001)\end{array}$ & $\begin{array}{l}0.000 \\
(0.001)\end{array}$ & $\begin{array}{c}0.002 \\
(0.003)\end{array}$ & & $\begin{array}{c}0.001 \\
(0.000)\end{array}$ & $\begin{array}{c}0.006^{* *} \\
(0.002)\end{array}$ & $\begin{array}{c}-0.001 \\
(0.001)\end{array}$ & & $\begin{array}{c}-0.001 \\
(0.004)\end{array}$ & $\begin{array}{c}0.011^{*} \\
(0.006)\end{array}$ & $\begin{array}{c}-0.012^{* *} \\
(0.001)\end{array}$ \\
\hline$i_{t-1}^{*}-i_{t-1}$ & $\begin{array}{c}0.500 \\
(1.085)\end{array}$ & $\begin{array}{l}2.048 \\
(3.111)\end{array}$ & $\begin{array}{c}-2.244 \\
(1.882)\end{array}$ & & $\begin{array}{l}1.219 \\
(0.783)\end{array}$ & $\begin{array}{c}18.852 \\
(22.188)\end{array}$ & $\begin{array}{c}0.222 \\
(0.552)\end{array}$ & & $\begin{array}{c}-4.059 \\
(0.174)\end{array}$ & $\begin{array}{c}28.899^{*} \\
(16.064)\end{array}$ & $\begin{array}{c}-0.430 \\
(5.701)\end{array}$ \\
\hline$\left(i_{t-1}^{*}-i_{t-1}\right) \cdot V X O_{t}$ & $\begin{array}{c}-0.020 \\
(0.038)\end{array}$ & $\begin{array}{c}-0.089 \\
(0.157)\end{array}$ & $\begin{array}{c}0.062 \\
(0.063)\end{array}$ & & $\begin{array}{c}-0.056 \\
(0.041)\end{array}$ & $\begin{array}{c}-1.242 \\
(1.589)\end{array}$ & $\begin{array}{c}0.001 \\
(0.030)\end{array}$ & & $\begin{array}{c}0.272 \\
(0.172)\end{array}$ & $\begin{array}{c}-2.029^{* *} \\
(0.940)\end{array}$ & $\begin{array}{c}0.267 \\
(0.223)\end{array}$ \\
\hline$\pi_{t-1}^{*}-\pi_{t-1}$ & $\begin{array}{c}0.813^{* * *} \\
(0.299)\end{array}$ & $\begin{array}{l}0.963^{* * *} \\
(0.295)\end{array}$ & $\begin{array}{c}0.399 \\
(0.528)\end{array}$ & & $\begin{array}{c}0.362 \\
(0.244)\end{array}$ & $\begin{array}{c}1.380^{*} \\
(0.787)\end{array}$ & $\begin{array}{c}0.183 \\
(0.170)\end{array}$ & & $\begin{array}{c}0.158 \\
(1.072)\end{array}$ & $\begin{array}{c}1.228 \\
(1.492)\end{array}$ & $\begin{array}{c}-0.224 \\
(1.473)\end{array}$ \\
\hline$u_{t-1}$ & $\begin{array}{c}-0.020 \\
(0.018)\end{array}$ & $\begin{array}{c}0.008 \\
(0.014)\end{array}$ & $\begin{array}{r}-0.100^{*} \\
(0.053)\end{array}$ & & $\begin{array}{c}-0.013 \\
(0.014)\end{array}$ & $\begin{array}{c}-0.098^{* *} \\
(0.050)\end{array}$ & $\begin{array}{c}-0.002 \\
(0.016)\end{array}$ & & $\begin{array}{c}-0.037^{* *} \\
(0.015)\end{array}$ & $\begin{array}{r}-0.100^{*} \\
(0.051)\end{array}$ & $\begin{array}{c}-0.044^{* *} \\
(0.018)\end{array}$ \\
\hline$\Delta m s c i w r_{t}$ & $\begin{array}{c}-0.176^{* * *} \\
(0.042)\end{array}$ & $\begin{array}{c}-0.070 \\
(0.048)\end{array}$ & $\begin{array}{c}-0.168^{* * *} \\
(0.062)\end{array}$ & & $\begin{array}{c}-0.141^{* * *} \\
(0.020)\end{array}$ & $\begin{array}{r}-0.150 \\
(0.139)\end{array}$ & $\begin{array}{c}-0.142^{* * *} \\
(0.020)\end{array}$ & & $\begin{array}{c}-0.040 \\
(0.096)\end{array}$ & $\begin{array}{c}-0.190 \\
(0.216)\end{array}$ & $\begin{array}{c}-0.071 \\
(0.106)\end{array}$ \\
\hline Obs. & 319 & 208 & 111 & & 319 & 75 & 244 & & 319 & 130 & 189 \\
\hline$R^{2}$ & 0.159 & 0.073 & 0.344 & & 0.118 & 0.204 & 0.179 & & 0.040 & 0.090 & 0.084 \\
\hline
\end{tabular}

Note: ${ }^{* *},{ }^{* *}$, and ${ }^{*}$ denote significance levels of 1,5 , or $10 \%$, respectively, based on robust standard errors. 
Table 10: Estimation results for bilateral EUR-based exchange rates with one regime

\begin{tabular}{rccc}
\hline & AUD & NZD & USD \\
\hline Const. & 0.003 & 0.003 & -0.001 \\
& $(0.002)$ & $(0.002)$ & $(0.002)$ \\
$i_{t-1}^{*}-i_{t-1}-0.499$ & -0.788 & -2.846 \\
& $(1.517)$ & $(1.561)$ & $(2.367)$ \\
$\left(i_{t-1}^{*}-i_{t-1}\right) \cdot V X O_{t}$ & -0.041 & 0.012 & 0.076 \\
& $(0.059)$ & $(0.057)$ & $(0.118)$ \\
$\pi_{t-1}^{*}-\pi_{t-1}$ & $2.102^{* * *}$ & 0.898 & $2.820^{* * *}$ \\
& $(0.657)$ & $(0.789)$ & $(0.576)$ \\
$u_{t-1}-0.037^{* *}$ & -0.061 & $-0.028^{* *}$ \\
& $(0.015)$ & $(0.020)$ & $(0.011)$ \\
$\Delta m s c i w r_{t}$ & $-0.341^{* * *}$ & $-0.168^{* * *}$ & -0.030 \\
& $(0.042)$ & $(0.043)$ & $(0.048)$ \\
\multicolumn{4}{c}{} \\
Obs. & 319 & 319 & 319 \\
$R^{2}$ & 0.216 & 0.176 & 0.085 \\
\hline
\end{tabular}

Note: $* * *, * *$, and $*$ denote significance levels of 1,5 , or $10 \%$, respectively, based on robust standard errors. 